\title{
Identified single-nucleotide polymorphisms and haplotypes at 16q22.1 increase diabetic nephropathy risk in Han Chinese population
}

\author{
Li-Na Liao ${ }^{1 \dagger}$, Ching-Chu Chen ${ }^{2,3 \dagger}$, Fang-Yang Wu' ${ }^{1}$, Cheng-Chieh Lin ${ }^{4,5}$, Jen-Hao Hsiao ${ }^{6}$, Chwen-Tzuei Chang ${ }^{2}$,
} Sharon LR Kardia', Tsai-Chung Li $\mathrm{i}^{8,9^{*}}$ and Fuu-Jen Tsai, ${ }^{3,10,11^{*}}$

\begin{abstract}
Background: Diabetic nephropathy (DN) has become one of the most common causes of end-stage renal disease (ESRD) in many countries, such as $44.5 \%$ in Taiwan. Previous studies have shown that there is a genetic component to ESRD. Studies attempting to determine which genetic variants are related to DN in Han Chinese are limited. A case-control study was conducted to identify DN susceptibility variants in Han Chinese patients with type 2 diabetes.

Results: We included 574 unrelated type 2 diabetes patients (217 DN cases and 357 controls), who were genotyped using Illumina HumanHap550-Duo BeadChip. In single-SNP association tests, the SNPs rs11647932, rs11645214, and rs6499323 located at 16q22.1 under the additive-effect disease model were significantly associated with an approximately 2-fold increased risk of DN. In haplotype association tests, identified haplotypes located in the chromosome 16q22.1 region (containing ST3GAL2, COG4, SF3B3, and IL34 genes) raised DN risk. The strongest association was found with haplotype rs2288491-rs4985534-rs1 1645214 (C-C-G) (adjusted odds ratio [AOR] 1.93, 95\% confidence interval [Cl] 1.83-2.03, $\mathrm{p}=6.25 \times 10^{-7}$ ), followed by haplotype rs8052125-rs2288491-rs4985534-rs1 1645214 (G-C-C-G) (AOR 1.92, 95\% Cl 1.82-2.02, $\mathrm{P}=6.56 \times 10^{-7}$ ), and haplotype rs2303792-rs8052125-rs2288491-rs4985534-rs11645214 (A-G-C-C-G) (AOR 1.91, 95\% Cl 1.81-2.01, $\mathrm{p}=1.15 \times 10^{-6}$ ).

Conclusions: Our results demonstrate that the novel SNPs and haplotypes located at the 16q22.1 region may involve in the biological pathways of DN in Han Chinese patients with type 2 diabetes. This study can provide new insights into the etiology of DN.
\end{abstract}

Keywords: Diabetic nephropathy, Single-nucleotide polymorphism, Haplotype, Han Chinese

\section{Background}

Diabetic nephropathy (DN) has become one of the most common causes of end-stage renal disease (ESRD) in many countries. In Taiwan, diabetes accounted for $44.5 \%$ of all new cases of ESRD [1], and more than $99 \%$ diabetes patients were with type 2 diabetes [2]. Diabetic ESRD patients had worse survival than non-diabetic ESRD patients [3].

It has been reported that genetic predisposition is one of the main risk factors for the development of DN [4]. Numerous familial aggregation studies have suggested that

\footnotetext{
* Correspondence: tcli@mail.cmu.edu.tw; d0704@mail.cmuh.org.tw ${ }^{\dagger}$ Equal contributors

${ }^{8}$ Graduate Institute of Biostatistics, College of Management, China Medical University, No. 91 Hsueh-Shih Road, Taichung 40402, Taiwan

${ }^{3}$ School of Chinese Medicine, College of Chinese Medicine, China Medical University, Taichung, Taiwan

Full list of author information is available at the end of the article
}

genetic susceptibility plays an important role in the development and progression of DN [5,6]. Epidemiologic studies have shown that $35 \%$ of patients with diabetes develop nephropathy, irrespective of glycemic control $[7,8]$.

Mooyaart et al. performed a meta-analysis to evaluate the pooled effect of each genetic variant reproducibly associated with DN [9]. They reported that 21 of 34 replicated genetic variants remained significantly associated with $\mathrm{DN}$. These 34 variants were in or near the following genes: ACE, ELMO1, $P P A R G$, etc. Recently, several genome-wide association studies (GWASs) have attempted to detect genetic variants associated with the risk of $\mathrm{DN}$ or diabetic ESRD in those of Japanese [10], Pima Indian [11], and African American [12] with type 2 diabetes, as well as European ancestry [13,14] with type 1 diabetes. 
Studies attempting to determine which genetic variants are related to DN in Han Chinese patients with type 2 diabetes are limited. In the present genetic association study, a case-control study was carried out to identify DN susceptibility variants in Han Chinese patients with type 2 diabetes, which can provide new insights into the etiology of DN.

\section{Methods}

\section{Study subjects}

Individuals with type 2 diabetes and aged over 20 years were recruited using the American Diabetes Association (ICD-9-CM, Diagnosis code 250) criteria for diagnosis of type 2 diabetes. Individuals with type 1 diabetes, gestational diabetes, and maturity-onset diabetes of the young were excluded. The dataset used is part of the whole dataset for the published paper titled "A Genome-wide Association Study Identifies Susceptibility Variants for Type 2 Diabetes in Han Chinese" [15]. A total of 995 type 2 diabetes subjects recruited from China Medical University Hospital were included in the current study. All patients with type 2 diabetes were of Han Chinese origin, including Minnan, Hakka, and Mainland Chinese. Individuals with significant aboriginal ancestry were excluded by using selfadministered questionnaires with six items regarding the ancestral origin of their parents and grandparents. Chronic kidney disease (CKD) was determined by estimated glomerular filtration rate (eGFR) and urine protein. Diabetic patients with eGFR $<60 \mathrm{~mL} / \mathrm{min} / 1.73 \mathrm{~m}^{2}$ or with proteinuria determined by a spot urine dipstick of $>1+$ were defined as DN cases. A total of $217 \mathrm{DN}$ cases were eligible for the study. To increase comparability between DN cases and controls, 357 controls were randomly selected based on frequency-matching of their age and durations of diabetes. This study was approved by the Human Research Committee of China Medical University Hospital. All patients signed informed consent forms.

\section{Measurements}

Blood samples were collected in the morning after a 12-h overnight fast and were sent for analysis within 4-h of collection. Spot morning urine samples were collected. Triglycerides, total cholesterol, high-density lipoprotein cholesterol (HDL-C), low-density lipoprotein cholesterol (LDL-C), creatinine, blood urea nitrogen (BUN), and uric acid were measured by a biochemical autoanalyser (Beckman Coulter, Synchron LX20, Fullerton, CA, USA). Renal function was evaluated by eGFR, which was estimated by using the Modification of Diet in Renal Disease Study equation for Taiwanese: eGFR $\left(\mathrm{ml} / \mathrm{min} / 1.73 \mathrm{~m}^{2}\right)=175 \times$ (serum creatinine $(\mathrm{mg} / \mathrm{dL})^{-1.154} \times(\text { age })^{-0.203} \times(0.742$ if female) $\times 0.945$ [16]. We also used the Chronic Kidney Disease Epidemiology Collaboration equation to obtain eGFR [17]. The proportions of eGFR $<60 \mathrm{~mL} / \mathrm{min} / 1.73 \mathrm{~m}^{2}$ by using above two equations were similar. A spot urine dipstick test was used for detecting proteinuria. Patients with a positive dipstick test $(>1+)$ were classified as with proteinuria [18]. The sociodemographic and lifestyle characteristics and the self-reported health status for each subject were recorded using self-administered questionnaires.

\section{Genotyping and quality control}

Genomic DNA from peripheral blood was prepared using the Puregene DNA isolation kit (Gentra Systems, Minneapolis, MN, USA). Our samples were genotyped using Illumina HumanHap550-Duo BeadChip, which was performed by deCODE Genetics (Reykjavík, Iceland). Genotypes were called using the standard procedure in BeadStudio (Illumina, Inc., San Diego, CA, USA), with the default parameters recommended by the platform manufacturer. The genotyping quality control procedures used to identify and remove poor-quality data were described previously [15]. Individual SNPs were excluded if they had a total call rate $<95 \%$ across all individuals, a minor allele frequency $<5 \%$ and a total call rate $<99 \%$, or had significant deviation from HardyWeinberg disequilibrium ( $\mathrm{p}$-value $<10^{-7}$ ) in these subjects. Further details of genotyping quality control procedures are available in the published study [15]. After SNPs quality control, 429,018 SNPs were used and their total call rate was $99.9 \%$. We also examined population stratification by using multidimensional scaling (MDS) analysis as implemented in PLINK. The results of MDS analysis showed that there was no evidence for population stratification.

\section{Statistical analysis}

Demographic and clinical characteristics of study subjects were examined, including sex, age, diabetes-related variables, behaviors, biochemical variables, and history of diseases. Continuous variables are reported as mean \pm standard deviation (SD), and categorical variables are reported as number and percentage. Two-sample $\mathrm{t}$ tests and Chi-square tests were used for the bivariate analyses. Because the distribution of the triglycerides was skewed, the data were normalized using a natural log-transformation, and the geometric mean \pm SD was calculated. To identify the DN susceptibility variants, single-SNP association tests using CochranArmitage trend test were performed. Then, multiple logistic regression analysis using an additive-effect disease model (an ordinal genotype model: 0,1 and 2 of a minor allele) was performed for each SNP with adjustment of the subject's sex, age, BMI, and durations of diabetes. The Bonferroni correction was used to adjust for multiple comparisons. P-value less than $10^{-4}$, association was considered to be statistically significant. According to previously published studies, as well as the results of single-SNP association tests and the Manhattan plot in our current study, 
potential susceptibility regions for $\mathrm{DN}$ were selected to perform haplotype analysis. In haplotype-based association analysis, the sliding window approach was adopted to detect haplotype effects. The window sizes of 3-SNP, 4-SNP, and 5-SNP haplotypes were used. Each haplotype with a frequency of $>0.05$ in this population was analyzed. Odds ratios (ORs) and their corresponding 95\% confidence intervals (CIs) were calculated to estimate the effect sizes of the identified SNPs and haplotypes. In addition, the linkage disequilibrium (LD) structures of the identified contiguous SNPs were examined. Pairwise LD was measured by the $r^{2}$ statistic. For power calculation of our case-control study (217 DN cases and 357 controls), Quanto software [19] was used. Under an additive effect disease model with a prevalence of $10 \%$ for $\mathrm{DN}$ (from our dataset), given a genetic relative risk of 1.85 and a disease allele frequency of $0.25-0.45$, the power of our study was $0.76-0.86$ at an alpha level of $10^{-4}$. All analyses were carried out using Haploview (v4.2) [20], PLINK (v1.07) (pngu.mgh.harvard.edu/purcell/ plink) [21], and SAS (v9.3, SAS Institute Inc, Cary, NC, USA) software. The regional plot was plotted from the LocusZoom, a web-based plotting tool (csg.sph.umich.edu/ locuszoom) [22]. The in silico prediction tool is-rSNP was used to predict potential regulatory SNPs (rSNPs) [23].

\section{Results}

Demographic and clinical characteristics of study samples A total of 574 type 2 diabetes study participants, comprising 217 cases of DN and 357 type 2 diabetes patients without DN controls, were included in the analysis. Table 1 shows the sociodemographic factors, diabetesrelated variables, lifestyle behaviors, biochemical variables, and history of diseases according to DN status. The mean age of the participants was about 62 years for both groups and their mean HbA1c at enrollment was $8.2 \pm 1.7 \%$ for the cases and $7.9 \pm 1.4 \%$ for the controls. The mean durations of diabetes were $11.1 \pm 7.7$ years for the cases and 10.2 \pm 7.2 years for the controls. Compared with the controls, DN cases had higher mean BMI, triglycerides, creatinine, uric acid, BUN, and prevalence of hypertension and heart disease.

\section{The graphical summary plot and single-SNP association tests}

The graphical summary plot of DN in single-SNP association analysis under additive-effect disease model is shown in Figure 1. There were four SNPs with p-value $<10^{-5}$ (above the red line), including rs10963767 (intron; ADAMTSL1 gene; 9p21.3), rs2058289 (intergenic; 12q24.3), rs11645214 (3' UTR; SF3B3 gene; 16q22.1), and rs6499323 (intron; IL34; 16q22.1). Furthermore, two signals with $\mathrm{p}$-value $<10^{-4}$ were observed, indicating the SNPs around this areas may be potential susceptibility variants for DN; one signal (rs876142, rs9928626, rs11647932, rs11645214, and rs6499323) was on chromosome 16 (16q21-16q22.1 regions) and the other (rs1028555, rs4815800, rs6065925, rs6131015, rs4812997, rs6074024, rs6127983, rs182784, rs1885580, rs7273764, rs6127999, rs6014975, rs4811839, rs6025517, and rs2426712) was on chromosome 20 (20p12.3 and 20q13.1-20q13.3 regions). Among these 15 SNPs on chromosome 20, only SNPs rs6127983 and rs182784 (intron; BMP7 gene; 20q13.3) and SNPs rs4811839 and rs6025517 (intron; RAE1 gene; 20q13.3) were inside of genes. A previous study reviewed in a meta-analysis by Mooyaart et al. showed that the Hp 1/2 variant in the HP gene (located at 16q22.2) was associated with DN. Therefore, a total of 383 genotyped SNPs at the 16q22.1-16q22.2 regions were selected for this study. Significant SNPs (p-value $<10^{-4}$ ) identified from single-SNP association analysis, along with the other 8 SNPs identified from haplotype association analysis, are presented in Table 2. The SNP with the lowest p-value $\left(6.25 \times 10^{-7}\right)$ was rs11645214 located on chromosome 16q22.1. This SNP, with a higher risk of DN (adjusted odds ratio [AOR] 1.94, 95\% confidence interval [CI] 1.49-2.51), is inside the SF3B3 gene (Additional file 1: Figure S1). Two other SNPs that showed a significant or borderline significant association with DN, each with an additive-effect, were rs6499323 (IL34) and rs11647932 (ST3GAL2) on chromosome 16q22.1 (Additional file 1: Figure $S 1)$. No significant variants were detected for $\mathrm{DN}$ at the $16 \mathrm{q} 22.2$ region.

\section{The LD structures and haplotypic association tests}

Pairwise LDs among the 11 SNPs located at 16q22.1 region are shown in Figure 2. SNPs rs8062183 in ST3GAL2, rs2303792 and rs8052125 in COG4, and rs2288491 in SF3B3 were in strong LD with each other $\left(r^{2}>0.94\right)$. SNP rs11645214 in SF3B3 was highly in LD with rs6499323 in IL34 $\left(r^{2}=0.92\right)$. Nevertheless, SNP rs11647932 and other SNPs were not in LD with $r^{2}$ values ranging from 0.04 to 0.30 .

Genotyped SNPs at the 16q22.1-16q22.2 regions were selected for the haplotypic association tests in this study. The window sizes of 3-SNP, 4-SNP, and 5-SNP haplotypes were used to detect haplotype effects on $\mathrm{DN}$, and a frequency of $>0.05$ was analyzed. The haplotypes with a pvalue $<10^{-4}$ are listed in Table 3 . There were 4,3 , and 4 haplotypes with p-value $<10^{-5}$ in window size of 3-SNP, 4SNP, and 5-SNP significantly associated with DN in this sample, respectively, after adjusted for sex, age, BMI, and durations of diabetes. In particular, haplotype rs2288491-rs4985534-rs11645214 (C-C-G) (AOR 1.93, 95\% CI 1.83-2.03, $\mathrm{p}=6.25 \times 10^{-7}$ ), haplotype rs8052125rs2288491-rs4985534-rs11645214 (G-C-C-G) (AOR 1.92, $95 \%$ CI 1.82-2.02, $\mathrm{p}=6.56 \times 10^{-7}$ ), and haplotype rs2303792rs8052125-rs2288491-rs4985534-rs11645214 (A-G-C-C-G) (AOR 1.91, 95\% CI 1.81-2.01, p = $1.15 \times 10^{-6}$ ) seem to be associated with a higher risk of DN. All haplotypes 
Table 1 Demographic and clinical characteristics of study samples

\begin{tabular}{|c|c|c|c|}
\hline Characteristics & Cases $(n=217)$ & Controls $(n=357)$ & p-value \\
\hline \multicolumn{4}{|l|}{ Sociodemographic factors } \\
\hline Male & $108(49.8)$ & $170(47.6)$ & 0.617 \\
\hline Age at enrollment (years) & $62.9 \pm 9.1$ & $62.6 \pm 9.2$ & 0.673 \\
\hline \multicolumn{4}{|l|}{ Diabetes-related variables } \\
\hline Age at onset of type 2 diabetes (years) & $51.8 \pm 9.4$ & $52.4 \pm 9.1$ & 0.463 \\
\hline Durations of diabetes (years) & $11.1 \pm 7.7$ & $10.2 \pm 7.2$ & 0.154 \\
\hline $\mathrm{HbA1c}$ at enrollment (\%) & $8.2 \pm 1.7$ & $7.9 \pm 1.4$ & 0.043 \\
\hline BMI $\left(\mathrm{kg} / \mathrm{m}^{2}\right)$ & $26.0 \pm 3.9$ & $24.7 \pm 3.5$ & $<0.001$ \\
\hline \multicolumn{4}{|l|}{ Lifestyle behaviors } \\
\hline Regular exercise & $123(56.7)$ & $260(72.8)$ & $<0.001$ \\
\hline Smoking status & & & 0.926 \\
\hline Ever & $33(15.2)$ & $52(14.6)$ & \\
\hline Yes & $36(16.6)$ & $56(15.7)$ & \\
\hline Alcohol drinking & & & 0.032 \\
\hline Ever & $20(9.2)$ & $14(3.9)$ & \\
\hline Yes & $34(15.7)$ & $63(17.7)$ & \\
\hline \multicolumn{4}{|l|}{ Biochemical variables } \\
\hline Triglycerides $(\mathrm{mg} / \mathrm{dL})^{\mathrm{a}}$ & $156.8 \pm 1.8$ & $131.1 \pm 1.8$ & $<0.001$ \\
\hline Total cholesterol (mg/dL) & $192.8 \pm 53.8$ & $185.9 \pm 37.2$ & 0.099 \\
\hline $\mathrm{HDL}-\mathrm{C}(\mathrm{mg} / \mathrm{dL})$ & $47.0 \pm 13.9$ & $49.4 \pm 13.7$ & 0.042 \\
\hline LDL-C (mg/dL) & $118.1 \pm 42.2$ & $117.5 \pm 33.3$ & 0.856 \\
\hline Creatinine (mg/dL) & $1.4 \pm 1.1$ & $0.7 \pm 0.2$ & $<0.001$ \\
\hline Uric Acid (mg/dL) & $7.4 \pm 1.9$ & $5.9 \pm 1.4$ & $<0.001$ \\
\hline BUN (mg/dL) & $24.9 \pm 12.7$ & $15.4 \pm 4.0$ & $<0.001$ \\
\hline Proteinuria & $125(57.9)$ & $0(0.0)$ & $<0.001$ \\
\hline eGFR $<60 \mathrm{ml} / \mathrm{min} / 1.73 \mathrm{~m}^{2}$ & $149(68.7)$ & $0(0.0)$ & $<0.001$ \\
\hline \multicolumn{4}{|l|}{ History of diseases } \\
\hline Hypertension & $140(64.5)$ & $156(43.7)$ & $<0.001$ \\
\hline Heart disease & $67(30.9)$ & $64(17.9)$ & $<0.001$ \\
\hline Stroke & $17(7.8)$ & $15(4.2)$ & 0.066 \\
\hline Diabetic retinopathy & $41(18.9)$ & $41(11.5)$ & 0.014 \\
\hline Diabetic foot & $9(4.2)$ & $5(1.4)$ & 0.039 \\
\hline
\end{tabular}

Data were presented as mean \pm SD for continuous variables or $\mathrm{n}(\%)$ for categorical variables. eGFR: estimated glomerular filtration rate; BUN: blood urea nitrogen. ${ }^{\mathrm{a} G e o m e t r i c ~ m e a n ~ w a s ~ p r e s e n t e d . ~}$

with significant associations with DN consisted of SNPs that exerted significant associations with DN in singleSNP association analysis.

\section{Discussion}

There is very limited evidence that any of genetic variants contribute to $\mathrm{DN}$ in Han Chinese populations. In this study, we expand on the previous investigation by Tsai et al. [15], which described compelling evidence of an association of type 2 diabetes with polymorphisms. We found that p-values of four SNPs were less than $10^{-5}$ in the Figure 1, and two signals, i.e. p-value $<10^{-4}$, were observed. We identified 11 SNPs in four loci located in $16 q 22.1$ that were associated with $\mathrm{DN}$ in a Han Chinese population. As a consequence, we were able to identify novel loci specifically associated with DN. Two SNPs of two loci with p-values in the $10^{-5}$ to $10^{-7}$ range were identified for DN. These include SNPs rs11645214 (SF3B3) and rs6499323 (IL34), with about a 2-fold increased risk of $\mathrm{DN}$. In the haplotype association analysis, 15 haplotypes, including these three SNPs (rs11647932, rs11645214, and rs6499323), carried an approximately 2-fold increased risk of DN, which further confirmed the findings of the singleSNP association tests. 


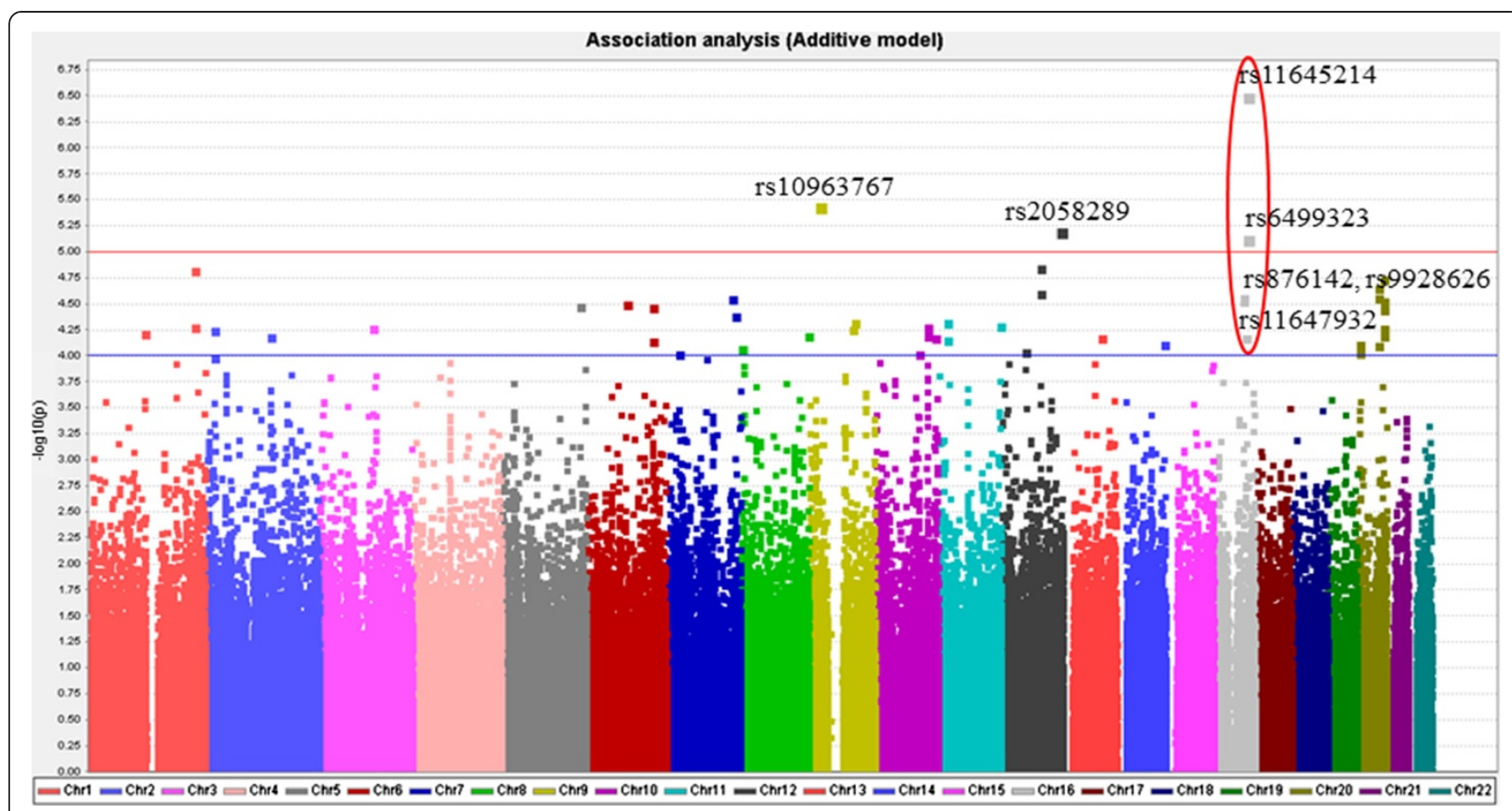

Figure 1 Graphical summary of DN in single-SNP association analysis under additive-effect disease model.

Previous studies using GWAS approach on DN in different racial groups have been conducted [10-14]. These studies showed that different polymorphisms in or near genes may be related to DN susceptibility, for example, intron $18+9170$ (ELMO1) in Japanese with type 2 diabetes [10]; rs2648875 (PVT1) and rs2720709 (PVT1) in Pima Indians with type 2 diabetes [11]; rs6930576 (SASH1), rs7769051 (near RPS12), rs2358944 (MSRB3 HMGA2), rs2106294 (LIMK2), rs4820043 (LIMK2), rs7735506 $(A U H)$, and rs5749286 (SFI1) in African Americans with type 2 diabetes [12]; rs10868025 (near FRMD3), rs1888747 (near FRMD3), rs451041 (CARS), and rs739401 (CARS) in European ancestry with type 1 diabetes [13]; and rs12437854 (RGMA MCTP2), rs7583877 (AFF3), and rs7588550 (ERBB4) in European ancestry with type 1 diabetes [14] (Additional file 1: Table S1). The susceptibility variants for DN varied widely among different population groups, which may be due to ethnic differences and genetic backgrounds. In this study, we found that polymorphisms in the ST3GAL2, COG4, SF3B3, IL34, and BMP7 genes may contribute to DN susceptibility in Han Chinese residing in Taiwan. In previous candidate gene studies, these genes have not been reported for DN in Han Chinese (Additional file 1: Table S2). The proportions of minor alleles of SNPs rs11647932 and rs6499323 among Taiwanese (14\% and 34\%, respectively) were similar to those of Han Chinese in China (CHB: 14\% and 36\%), but higher than those of Japanese (JPT: 12\% and 28\%), Europeans (CEU: $12 \%$ and 20\%), and Africans (YRI: 0\% and 12\%) [24].
Many plausible mechanisms have been hypothesized to be involved in the association between $\mathrm{DN}$ and identified SNPs. First, the protein encoded by the ST3GAL2 gene mapped on chromosome 16q22.1 catalyzes the transfer of sialic acid from CMP-sialic acid to galactose-containing substrates [25]. Sialic acid is one of the inflammatory biomarkers of the acute-phase response and is a possible risk factor for cardiovascular disease [26]. Sialic acid was synthesized as a result of cytokines released by inflammatory cells and damaged endothelia due to angiopathyassociated tissue injury [26]. This cytokine response could directly result in vasculopathy in diabetes through atherosclerosis [26]. Moreover, cross-sectional and longitudinal studies have shown that elevated serum sialic acid concentrations are related to diabetic microvascular complications (including $\mathrm{DN}$ ) in type 2 diabetes $[27,28]$ or type 1 diabetes $[29,30]$. A strong association between increased serum sialic acid concentrations and macrovascular complications (coronary heart disease; $\mathrm{CHD}$ ) in type 2 diabetes was also observed [31]. In addition, a 7-year prospective cohort study revealed that a raised serum sialic acid concentration is associated with CHD in type 1 diabetes [32].

Second, the protein encoded by the COG4 (a component of oligomeric golgi complex 4) gene, including COG4, is critical for the structure and function of the Golgi apparatus and can influence intracellular membrane trafficking, including the addition and processing of carbohydrates (glycosylation) in the rough endoplasmic reticulum and Golgi [33,34]. Mutations in COG4 may lead to abnormal functioning in the Golgi apparatus, resulting 
Table 2 Single-SNP association analysis for DN at the 16q22.1-16q22.2 regions under the additive model ${ }^{\mathrm{a}}$

\begin{tabular}{|c|c|c|c|c|c|c|c|c|c|}
\hline SNP & Minor (major) allele & MAF (Cases) & MAF (Controls) & Gene & Location & Crude OR $(95 \% \mathrm{Cl})$ & $p$-value ${ }^{b}$ & Adjusted OR $(95 \% \mathrm{Cl})$ & $p$-value ${ }^{c}$ \\
\hline rs4985526 & $\mathrm{T}(\mathrm{C})$ & 0.26 & 0.33 & ST3GAL2 & intron & $0.71(0.55-0.93)$ & $1.26 \mathrm{E}-02$ & $0.72(0.55-0.95)$ & $1.79 \mathrm{E}-02$ \\
\hline rs11647932 & $\mathrm{T}(\mathrm{C})$ & 0.24 & 0.14 & ST3GAL2 & intron & $1.84(1.36-2.50)$ & $6.39 \mathrm{E}-05$ & $1.82(1.34-2.48)$ & 1.37E-04 \\
\hline rs8062183 & $A(G)$ & 0.35 & 0.45 & ST3GAL2 & near-gene-5 & $0.68(0.53-0.87)$ & $2.19 \mathrm{E}-03$ & $0.69(0.53-0.88)$ & 3.55E-03 \\
\hline rs2303792 & $G(A)$ & 0.35 & 0.44 & COG4 & intron & $0.68(0.53-0.88)$ & $2.54 \mathrm{E}-03$ & $0.69(0.53-0.89)$ & 4.05E-03 \\
\hline rs8052125 & $\mathrm{T}(\mathrm{G})$ & 0.35 & 0.44 & COG4 & intron & $0.67(0.52-0.86)$ & $1.68 \mathrm{E}-03$ & $0.68(0.52-0.87)$ & $2.79 \mathrm{E}-03$ \\
\hline rs2288491 & $\mathrm{T}(\mathrm{C})$ & 0.35 & 0.44 & SF3B3 & intron & $0.68(0.53-0.88)$ & 2.62E-03 & $0.69(0.53-0.89)$ & $3.91 \mathrm{E}-03$ \\
\hline rs4985534 & $\mathrm{T}(\mathrm{C})$ & 0.24 & 0.31 & SF3B3 & intron & $0.69(0.53-0.90)$ & $6.91 \mathrm{E}-03$ & $0.69(0.52-0.91)$ & $8.23 \mathrm{E}-03$ \\
\hline rs11645214 & $G(A)$ & 0.49 & 0.33 & SF3B3 & 3' UTR & $1.92(1.49-2.48)$ & 3.07E-07 & $1.94(1.49-2.51)$ & $6.25 \mathrm{E}-07$ \\
\hline rs6499323 & $G(A)$ & 0.47 & 0.34 & IL34 & intron & $1.77(1.38-2.28)$ & 7.24E-06 & $1.81(1.40-2.35)$ & 7.10E-06 \\
\hline rs7197333 & $C(T)$ & 0.16 & 0.21 & IL34 & intron & $0.71(0.52-0.97)$ & 2.86E-02 & $0.69(0.51-0.95)$ & 2.20E-02 \\
\hline rs1006985 & $C(T)$ & 0.44 & 0.50 & IL34 & intron & $0.76(0.60-0.97)$ & 2.85E-02 & $0.75(0.58-0.96)$ & $2.18 \mathrm{E}-02$ \\
\hline
\end{tabular}

MAF: minor allele frequency.

${ }^{a}$ Significant SNPs $\left(p-v a l u e ~<10^{-4}\right.$ ) identified from single-SNP association analysis, along with the other 8 SNPs identified from haplotype association analysis, are presented.

${ }^{\mathrm{b}} \mathrm{p}$-value from Chi-square test (Cochran-Armitage trend test).

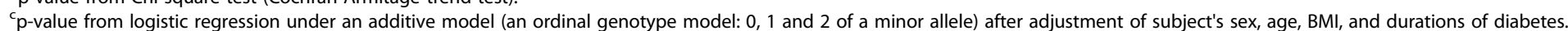




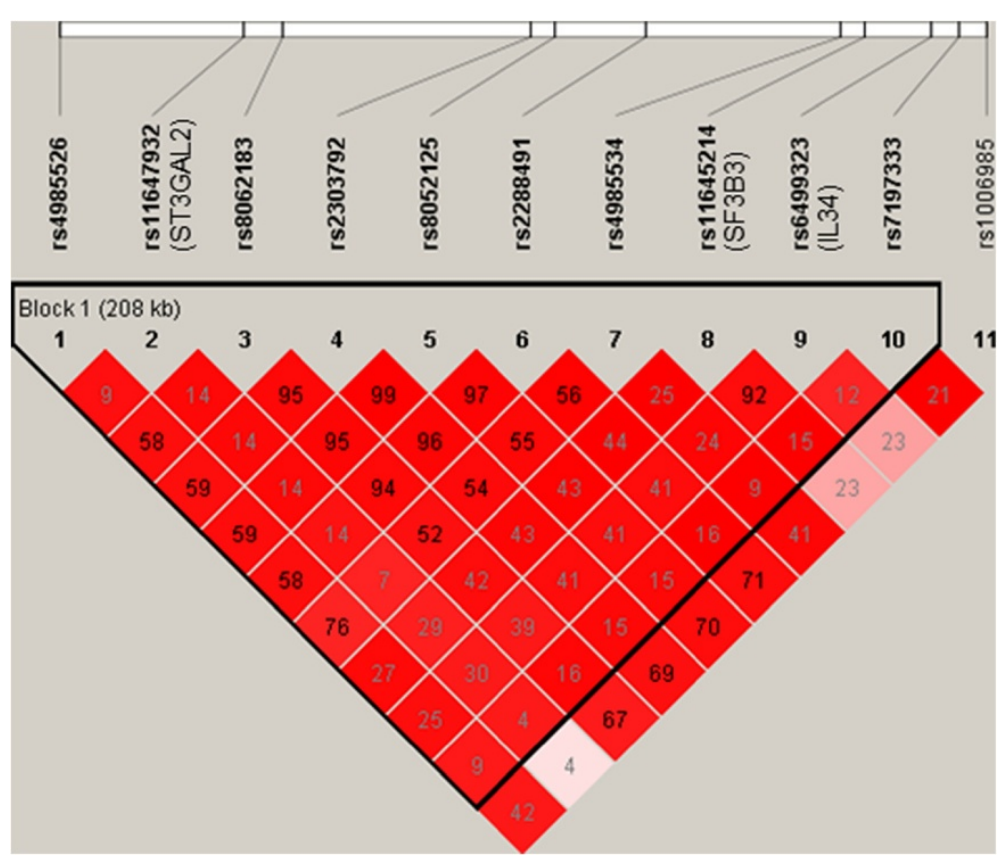

Figure 2 Pairwise linkage disequilibrium (LD) among the 11 SNPs located at $\mathbf{1 6 q 2 2 . 1}$ region. Pairwise LD was measured by the $r^{2}$ statistic An $r^{2}$ value of 1 indicates a complete LD between two SNPs, and an $r^{2}$ value of 0 indicates a perfect equilibrium. Lower $r^{2}$ value shows a lower degree of $L D$. Pairwise $D^{\prime}$ values along with LOD scores were displayed in different colors. White indicates $D^{\prime}<1$ and $L O D<2 ;$ blue indicate $D^{\prime}=1$ and LOD $<2$; bright red indicate $D^{\prime}=1$ and $L O D \geq 2$; shades of pink/red indicate $D^{\prime}<1$ and $L O D \geq 2$.

in an excessive amount of glucose circulating in the blood plasma. Diabetes mellitus is characterized by chronic hyperglycaemia. A number of studies have examined the relationship of hyperglycaemia, classified according to mean levels of HbA1c [35-37] or fasting plasma glucose $[38,39]$, with diabetic complications.

Third, the IL34 (interleukin 34) gene maps on chromosome 16q22.1. Interleukin 34 is a cytokine that promotes the differentiation and viability of monocytes and macrophages through the colony-stimulating factor1 receptor (CSF1R) [40], and the causative role of macrophages and/or monocytes in DN has been demonstrated by cell depletion studies in animal models [41,42]. Many studies have shown that inflammatory cytokines such as IL-1, IL-6, IL-18, and TNF- $\alpha$ are important in the pathogenesis of diabetic microvascular complications (including DN) [43]. Furthermore, previous studies have revealed that cytokine gene polymorphisms such as $I L-1, I L-6$, and TNF- $\alpha$ are related to DN [44]. Variants in IL34 may play a role in the pathogenesis of $\mathrm{DN}$ because of the highly correlated cytokine network, although there is no direct evidence for the association between IL34 gene polymorphisms and DN.

Fourth, the protein encoded by the BMP7 (bone morphogenetic protein 7) gene mapped on $20 \mathrm{q} 13.3$ is a member of the transforming growth factor-beta (TGF- $\beta$ ) superfamily, and is highly expressed in the kidney tubules and glomeruli [45]. Previous studies showed that TGF- $\beta$ cellular signaling is critical to the induction of glomerular and tubulointerstitial fibrosis in DN [46]. Animal studies demonstrated that the renal BMP7 protected against DN [47], and the BMP7 partially reversed kidney hypertrophy induced by diabetes, urine albumin excretion, restoring GFR, as well as glomerular histology toward normal [48]. McKnight et al. investigated the association of BMP gene variants with DN in White individuals with type 1 diabetes, and they reported that the common variants in $B M P 2, B M P 4$ and $B M P 7$ genes did not strongly influence genetic susceptibility to DN [49]. In our study, we found that two SNPs in BMP7 gene may be susceptibility variants of $\mathrm{DN}$ in Han Chinese patients with type 2 diabetes.

For predicting potential rSNPs, we used the in silico prediction tool is-rSNP [23]. The is-rSNP predicted that rs2058289, rs9928626, rs11647932, rs1028555, rs6127999, rs6131015, rs7273764, and rs4815800 are potential rSNPs; that is, they affect the binding affinity of a transcription factor to the DNA (Additional file 1: Table S3). For example, alleles of rs2058289 alter the binding affinity of Sp4_2 ( $p=0.021)$ and Eomes_1 ( $p=0.036)$; alleles of rs9928626 alter the binding affinity of LYS14 ( $p=0.018)$, YKL222C ( $\mathrm{p}=0.043$ ), and YDR520C ( $\mathrm{p}=0.043)$; and alleles of rs11647932 alter the binding affinity of LM226 $(\mathrm{p}=0.050)$. Furthermore, from the online Nephromine database (www.nephromine.org), there were some evidences in the literature that the expression of candidate genes in our study were associated with $\mathrm{DN}$ in 
Table 3 Haplotypic association tests for DN at the $16 q 22.1-16 q 22.2$ regions $^{a}$

\begin{tabular}{|c|c|c|c|c|c|c|c|}
\hline Haplotypes $^{\text {b }}$ & SNPs & $\mathrm{H}$-freq (Cases) & $\mathrm{H}$-freq (Controls) & Crude OR $(95 \% \mathrm{Cl})$ & $p$-value ${ }^{c}$ & Adjusted OR (95\% Cl) & $p$-value ${ }^{d}$ \\
\hline \multicolumn{8}{|c|}{ Window size of 3-SNP } \\
\hline $\mathrm{H} 1$ (C-T-G) & rs4985526-rs11647932-rs8062183 & 0.24 & 0.14 & $1.86(1.72-2.01)$ & 7.36E-05 & $1.84(1.70-1.99)$ & 1.10E-04 \\
\hline $\mathrm{H} 2(\mathrm{~T}-\mathrm{G}-\mathrm{A})$ & rs11647932-rs8062183-rs2303792 & 0.24 & 0.14 & $1.85(1.71-2.00)$ & $7.18 \mathrm{E}-05$ & $1.84(1.70-1.99)$ & $1.07 E-04$ \\
\hline H3 (C-C-G) & rs2288491-rs4985534-rs11645214 & 0.49 & 0.33 & $1.92(1.82-2.02)$ & 5.40E-07 & $1.93(1.83-2.03)$ & $6.25 \mathrm{E}-07$ \\
\hline $\mathrm{H} 4$ (C-G-G) & rs4985534-rs11645214-rs6499323 & 0.47 & 0.33 & $1.86(1.76-1.96)$ & 2.08E-06 & $1.90(1.80-2.01)$ & $1.48 \mathrm{E}-06$ \\
\hline H5 (G-G-T) & rs11645214-rs6499323-rs7197333 & 0.47 & 0.33 & $1.86(1.76-1.96)$ & $2.08 \mathrm{E}-06$ & $1.90(1.80-2.01)$ & $1.48 \mathrm{E}-06$ \\
\hline H6 (G-T-T) & rs6499323-rs7197333-rs1006985 & 0.39 & 0.27 & $1.73(1.62-1.84)$ & 4.42E-05 & $1.85(1.74-1.97)$ & 8.93E-06 \\
\hline \multicolumn{8}{|c|}{ Window size of 4-SNP } \\
\hline H7 (T-G-A-G) & rs11647932-rs8062183-rs2303792-rs8052125 & 0.24 & 0.14 & $1.85(1.71-2.00)$ & 8.22E-05 & $1.85(1.71-2.00)$ & $8.04 \mathrm{E}-05$ \\
\hline H8 (G-C-C-G) & rs8052125-rs2288491-rs4985534-rs11645214 & 0.48 & 0.33 & $1.91(1.81-2.01)$ & $6.99 \mathrm{E}-07$ & $1.92(1.82-2.02)$ & $6.56 \mathrm{E}-07$ \\
\hline H9 (C-C-G-G) & rs2288491-rs4985534-rs11645214-rs6499323 & 0.47 & 0.33 & $1.86(1.76-1.96)$ & $2.08 \mathrm{E}-06$ & $1.87(1.77-1.97)$ & $1.76 \mathrm{E}-06$ \\
\hline $\mathrm{H} 10$ (C-G-G-T) & rs4985534-rs11645214-rs6499323-rs7197333 & 0.47 & 0.33 & $1.86(1.76-1.96)$ & 2.08E-06 & $1.87(1.77-1.97)$ & $1.76 \mathrm{E}-06$ \\
\hline H11 (G-G-T-T) & rs11645214-rs6499323-rs7197333-rs1006985 & 0.39 & 0.27 & $1.74(1.63-1.86)$ & 4.63E-05 & $1.76(1.65-1.88)$ & $3.16 \mathrm{E}-05$ \\
\hline \multicolumn{8}{|c|}{ Window size of 5-SNP } \\
\hline $\mathrm{H} 12(\mathrm{~A}-\mathrm{G}-\mathrm{C}-\mathrm{C}-\mathrm{G})$ & rs2303792-rs8052125-rs2288491-rs4985534-rs11645214 & 0.48 & 0.33 & $1.90(1.80-2.00)$ & $9.62 \mathrm{E}-07$ & $1.91(1.81-2.01)$ & $1.15 \mathrm{E}-06$ \\
\hline H13 (G-C-C-G-G) & rs8052125-rs2288491-rs4985534-rs11645214-rs6499323 & 0.47 & 0.33 & $1.86(1.76-1.96)$ & 2.08E-06 & $1.90(1.80-2.01)$ & $1.48 \mathrm{E}-06$ \\
\hline H14 (C-C-G-G-T) & rs2288491-rs4985534-rs11645214-rs6499323-rs7197333 & 0.47 & 0.33 & $1.86(1.76-1.96)$ & 2.08E-06 & $1.90(1.80-2.01)$ & $1.48 \mathrm{E}-06$ \\
\hline H15 (C-G-G-T-T) & rs4985534-rs11645214-rs6499323-rs7197333-rs1006985 & 0.39 & 0.27 & $1.74(1.63-1.86)$ & 4.72E-05 & $1.85(1.74-1.97)$ & 9.85E-06 \\
\hline
\end{tabular}

H-freq: haplotype frequency

anly crude $p$-value $<10^{-4}$ was presented.

${ }^{\mathrm{b}} \mathrm{A}$ haplotype with a frequency of $>0.05$ was included in the analysis.

$c_{p}$-value from logistic regression.

${ }_{\mathrm{d}} \mathrm{p}$-value from logistic regression after adjustment of subject's sex, age, BMI, and durations of diabetes. 
human population (Additional file 1: Table S4) or mice (Additional file 1: Table S5).

The subjects in this study were a portion of the cohort studied in a published GWAS paper [15]. Although the sample size in this study was limited, the DN cases and the controls were much more homogeneous in terms of gender, age, durations of diabetes, and HbA1c level after excluding subjects with extreme characteristics and matching their age and durations of diabetes. A previous study found that the Han Chinese residing in Taiwan were relatively homogenous in genetic background, spread among the three major ethnic groups of Minnan, Hakka, and Mainland Chinese [50], which is consistent with the results of our population stratification analysis. Therefore, the impact of population stratification on our genetic association study is small.

\section{Conclusions}

We identified 3 novel SNPs (rs11647932, rs11645214, and rs6499323) and 11 haplotypes (4, 3, and 4 in window size of 3-SNP, 4-SNP, and 5-SNP, respectively), located at the 16q22.1 region, that are susceptibility variants of DN in a Han Chinese population in Taiwan. The findings reveal that the susceptibility variants located at the 16q22.1 region may involve in the biological pathways of DN in Han Chinese patients with type 2 diabetes. Our results can provide new insights into the etiology of DN.

\section{Additional file}

Additional file 1: Figure S1. Regional plot of these 11 SNPs located on chromosome $16 q 22.1$. The $-\log _{10}$ ( $p$-value) (left $y$-axis) was from the trend test using our data. The estimated $r^{2}$ and recombination rate (right $y$-axis) based on the HapMap Phase II JPT + CHB populations were plotted to reflect the LD structure. The gene information was from the UCSC (Build hg18). The regional plot was plotted from the LocusZoom, a web-based plotting tool (csg.sph.umich.edu/locuszoom). Table S1. Summary of identified polymorphisms through GWAS. Table S2. Summary of variants associated with nephropathy in Han Chinese patients with type 2 diabetes through candidate gene approach. Table S3. is-rSNP prediction results ${ }^{\mathrm{a}}$. Table S4. Gene expression from human diabetic nephropathy datasets in the Nephromine database. Table S5. Gene expression from Hodgin Diabetes Mouse dataset ${ }^{\mathrm{a}}$ in the Nephromine database [51-63].

\section{Abbreviations \\ DN: Diabetic nephropathy; ESRD: End-stage renal disease; CKD: Chronic kidney disease; eGFR: Estimated glomerular filtration rate; HDL-C: Hhigh-density lipoprotein cholesteroll; LDL-C: Low-density lipoprotein cholesterol; BUN: Blood urea nitrogen; MDS: Multidimensional scaling; LD: Linkage disequilibrium.}

\section{Competing interests}

The authors declare that they have no competing interests.

\section{Authors' contributions}

LNL, CCC, CCL, CTC, SLRK, JHH, TCL, and FJT carried out the conception and design, acquisition of data, and analysis and interpretation of data. LNL, FYW, and TCL drafted the article or revised it critically for important intellectual content. All authors read and approved the final manuscript.

\section{Acknowledgements}

We would like to thank all of the patients and study personnel who participated in this study. We also thank the Academia Sinica for technical support. This study was supported by the Academia Sinica (BM102010130), Ministry of Science and National Science Council Technology of Taiwan (NSC101-2314-B-039-017-MY3) and Ministry of Health \& Welfare Clinical Trial and Research Center of Excellence (MOHW103-TDU-B-212- 113002).

\section{Author details}

${ }^{1}$ Department of Public Health, College of Public Health, China Medical University, Taichung, Taiwan. ${ }^{2}$ Division of Endocrinology and Metabolism, Department of Medicine, China Medical University Hospital, Taichung, Taiwan. ${ }^{3}$ School of Chinese Medicine, College of Chinese Medicine, China Medical University, Taichung, Taiwan. ${ }^{4}$ Department of Family Medicine, China Medical University Hospital, Taichung, Taiwan. ${ }^{5}$ School of Medicine, College of Medicine, China Medical University, Taichung, Taiwan. ${ }^{6}$ Bioinformatics and Biostatistics Core, Center of Genomic Medicine, National Taiwan University, Taipei, Taiwan. ${ }^{7}$ Department of Epidemiology, University of Michigan, Ann Arbor, MI, USA. ${ }^{8}$ Graduate Institute of Biostatistics, College of Management, China Medical University, No. 91 Hsueh-Shih Road, Taichung 40402, Taiwan. ${ }^{9}$ Department of Healthcare Administration, College of Health Science, Asia University, Taichung, Taiwan. ${ }^{10}$ Department of Medical Genetics, China Medical University Hospital, Taichung, Taiwan. ${ }^{11}$ Department of Biotechnology and Bioinformatics, Asia University, Taichung, Taiwan.

Received: 28 April 2014 Accepted: 13 October 2014

Published online: 31 October 2014

\section{References}

1. Collins AJ, Foley RN, Chavers B, Gilbertson D, Herzog C, Johansen K, Kasiske B, Kutner N, Liu J, St Peter W, Guo H, Gustafson S, Heubner B, Lamb K, Li S, Li S, Peng Y, Qiu Y, Roberts T, Skeans M, Snyder J, Solid C, Thompson B, Wang C, Weinhandl E, Zaun D, Arko C, Chen SC, Daniels F, Ebben J: United States Renal Data System 2011 Annual Data Report: Atlas of chronic kidney disease \& end-stage renal disease in the United States. Am J Kidney Dis 2012, 59(A7):e1-e420.

2. Jiang YD, Chang CH, Tai TY, Chen JF, Chuang LM: Incidence and prevalence rates of diabetes mellitus in Taiwan: analysis of the 20002009 Nationwide Health Insurance database. J Formos Med Assoc 2012, 111:599-604.

3. Yang WC, Hwang SJ: Incidence, prevalence and mortality trends of dialysis end-stage renal disease in Taiwan from 1990 to 2001: the impact of national health insurance. Nephrol Dial Transplant 2008, 23:3977-3982.

4. Gross JL, de Azevedo MJ, Silveiro SP, Canani LH, Caramori ML, Zelmanovitz $\mathrm{T}$ : Diabetic nephropathy: diagnosis, prevention, and treatment. Diabetes Care 2005, 28:164-176.

5. Seaquist ER, Goetz FC, Rich S, Barbosa J: Familial clustering of diabetic kidney disease. Evidence for genetic susceptibility to diabetic nephropathy. N Engl J Med 1989, 320:1161-1165.

6. Imperatore G, Knowler WC, Pettitt DJ, Kobes S, Bennett PH, Hanson RL: Segregation analysis of diabetic nephropathy in Pima Indians. Diabetes 2000, 49:1049-1056.

7. Andersen AR, Christiansen JS, Andersen JK, Kreiner S, Deckert T: Diabetic nephropathy in Type 1 (insulin-dependent) diabetes: an epidemiological study. Diabetologia 1983, 25:496-501.

8. Krolewski AS, Warram JH, Christlieb AR, Busick EJ, Kahn CR: The changing natural history of nephropathy in type I diabetes. Am J Med 1985, 78:785-794

9. Mooyaart AL, Valk EJ, van Es LA, Bruijn JA, de Heer E, Freedman BI, Dekkers $\mathrm{OM}$, Baelde $\mathrm{HJ}$ : Genetic associations in diabetic nephropathy: a metaanalysis. Diabetologia 2011, 54:544-553.

10. Shimazaki A, Kawamura Y, Kanazawa A, Sekine A, Saito S, Tsunoda T, Koya D, Babazono T, Tanaka Y, Matsuda M, Kawai K, liizumi T, Imanishi M, Shinosaki T, Yanagimoto T, Ikeda M, Omachi S, Kashiwagi A, Kaku K, Iwamoto Y, Kawamori R, Kikkawa R, Nakajima M, Nakamura Y, Maeda S: Genetic variations in the gene encoding ELMO1 are associated with susceptibility to diabetic nephropathy. Diabetes 2005, 54:1171-1178.

11. Hanson RL, Craig DW, Millis MP, Yeatts KA, Kobes S, Pearson JV, Lee AM, Knowler WC, Nelson RG, Wolford JK: Identification of PVT1 as a candidate gene for end-stage renal disease in type 2 diabetes using a pooling- 
based genome-wide single nucleotide polymorphism association study. Diabetes 2007, 56:975-983.

12. McDonough CW, Palmer ND, Hicks PJ, Roh BH, An SS, Cooke JN, Hester JM, Wing MR, Bostrom MA, Rudock ME, Lewis JP, Talbert ME, Blevins RA, Lu L, Ng MC, Sale MM, Divers J, Langefeld CD, Freedman BI, Bowden DW: A genome-wide association study for diabetic nephropathy genes in African Americans. Kidney Int 2011, 79:563-572.

13. Pezzolesi MG, Poznik GD, Mychaleckyj JC, Paterson AD, Barati MT, Klein JB, Ng DP, Placha G, Canani LH, Bochenski J, Waggott D, Merchant ML, Krolewski B, Mirea L, Wanic K, Katavetin P, Kure M, Wolkow P, Dunn JS, Smiles A, Walker WH, Boright AP, Bull SB, Doria A, Rogus JJ, Rich SS, Warram $J H$, Krolewski AS, DCCT/EDIC Research Group: Genome-wide association scan for diabetic nephropathy susceptibility genes in type 1 diabetes. Diabetes 2009, 58:1403-1410.

14. Sandholm N, Salem RM, McKnight AJ, Brennan EP, Forsblom C, Isakova T, McKay GJ, Williams WW, Sadlier DM, Makinen VP, Swan EJ, Palmer C, Boright AP, Ahlqvist E, Deshmukh HA, Keller BJ, Huang H, Ahola AJ, Fagerholm E, Gordin D, Harjutsalo V, He B, Heikkilä O, Hietala K, Kytö J, Lahermo P, Lehto M, Lithovius R, Osterholm AM, Parkkonen M, et al: New susceptibility loci associated with kidney disease in type 1 diabetes. PLoS Genet 2012, 8:e1002921.

15. Tsai FJ, Yang CF, Chen CC, Chuang LM, Lu CH, Chang CT, Wang TY, Chen RH, Shiu CF, Liu YM, Chang CC, Chen P, Chen CH, Fann CS, Chen YT, Wu JY: A genome-wide association study identifies susceptibility variants for type 2 diabetes in Han Chinese. PLoS Genet 2010, 6:1000847.

16. The Report of Chronic Kidney Disease Prevention, 2011 [in Chinese]. [http://health99.hpa.gov.tw/Hot_News/h_NewsDetailN.aspx? Toplc $\mathrm{No}=6459]$

17. Levey AS, Stevens LA, Schmid CH, Zhang YL, Castro AF 3rd, Feldman HI, Kusek JW, Eggers P, Van Lente F, Greene T, Van Lente F, Greene T, Coresh J, CKD-EP (Chronic Kidney Disease Epidemiology Collaboration): A new equation to estimate glomerular filtration rate. Ann Intern Med 2009, 150:604-612.

18. NKF: K/DOQI clinical practice guidelines for chronic kidney disease: evaluation, classification, and stratification. Am J Kidney Dis 2002, 39:S1-S266.

19. Gauderman WJ, Morrison JM: QUANTO 1.1: A computer program for power and sample size calculations for genetic-epidemiology studies, http://hydra.usc.edu/gxe. 2006

20. Barrett JC, Fry B, Maller J, Daly MJ: Haploview: analysis and visualization of LD and haplotype maps. Bioinformatics 2005, 21:263-265.

21. Purcell S, Neale B, Todd-Brown K, Thomas L, Ferreira MA, Bender D, Maller J, Sklar P, de Bakker PI, Daly MJ, Sham PC: PLINK: a tool set for wholegenome association and population-based linkage analyses. Am J Hum Genet 2007, 81:559-575.

22. Pruim RJ, Welch RP, Sanna S, Teslovich TM, Chines PS, Gliedt TP, Boehnke M, Abecasis GR, Willer CJ: LocusZoom: regional visualization of genome-wide association scan results. Bioinformatics 2010, 26:2336-2337.

23. Macintyre G, Bailey J, Haviv I, Kowalczyk A: is-rSNP: a novel technique for in silico regulatory SNP detection. Bioinformatics 2010, 26:1524-i530

24. Data Rel 27 Phase II+III, Feb 09. International HapMap Consortium. http:// hapmap.ncbi.nIm.nih.gov. Accessed May 21, 2013.

25. Taniguchi A, Morishima T, Tsujita Y, Matsumoto Y, Matsumoto K: Genomic structure, expression, and transcriptional regulation of human Gal beta 1,3 GalNAc alpha 2,3-sialyltransferase gene. Biochem Biophys Res Commun 2003, 300:570-576.

26. Gopaul KP, Crook MA: Sialic acid: a novel marker of cardiovascular disease? Clin Biochem 2006, 39:667-681

27. Chen J, Gall MA, Yokoyama H, Jensen JS, Deckert M, Parving HH: Raised serum sialic acid concentration in NIDDM patients with and without diabetic nephropathy. Diabetes Care 1996, 19:130-134.

28. Nayak BS, Roberts L: Relationship between inflammatory markers, metabolic and anthropometric variables in the Caribbean type 2 diabetic patients with and without microvascular complications. J Inflamm 2006, 3:17.

29. Crook MA, Pickup JC, Lumb PJ, Giorgino F, Webb DJ, Fuller JH, Group EICS: Relationship between plasma sialic acid concentration and microvascular and macrovascular complications in type 1 diabetes: the EURODIAB Complications Study. Diabetes Care 2001, 24:316-322.

30. Yokoyama H, Jensen JS, Myrup B, Mathiesen ER, Ronn B, Deckert T: Raised serum sialic acid concentration precedes onset of microalbuminuria in IDDM. A 10-year follow-up study. Diabetes Care 1996, 19:435-440.
31. Pickup JC, Mattock MB, Crook MA, Chusney GD, Burt D, Fitzgerald AP: Serum sialic acid concentration and coronary heart disease in NIDDM. Diabetes Care 1995, 18:1100-1103

32. Soedamah-Muthu SS, Chaturvedi N, Pickup JC, Fuller JH, Group EPCS: Relationship between plasma sialic acid and fibrinogen concentration and incident micro- and macrovascular complications in type 1 diabetes. The EURODIAB Prospective Complications Study (PCS). Diabetologia 2008, 51:493-501.

33. Lodish H, Berk A, Matsudaira P, Kaiser CA, Krieger M, Scott MP, Zipursky L, Darnell J: Molecular Cell Biology. New York: W.H. Freeman and Company; 2004

34. Ungar D, Oka T, Brittle EE, Vasile E, Lupashin W, Chatterton JE, Heuser JE, Krieger M, Waters MG: Characterization of a mammalian Golgi-localized protein complex, $\mathrm{COG}$, that is required for normal Golgi morphology and function. J Cell Biol 2002, 157:405-415.

35. Hemmingsen B, Lund SS, Gluud C, Vaag A, Almdal T, Hemmingsen C, Wetterslev J: Intensive glycaemic control for patients with type 2 diabetes: systematic review with meta-analysis and trial sequential analysis of randomised clinical trials. BMJ 2011, 343:d6898.

36. Tu ST, Chang SJ, Chen JF, Tien KJ, Hsiao JY, Chen HC, Hsieh MC: Prevention of diabetic nephropathy by tight target control in an asian population with type 2 diabetes mellitus: a 4-year prospective analysis. Arch Intern Med 2010, 170:155-161.

37. UKPDS: Intensive blood-glucose control with sulphonylureas or insulin compared with conventional treatment and risk of complications in patients with type 2 diabetes (UKPDS 33). UK Prospective Diabetes Study (UKPDS) Group. Lancet 1998, 352:837-853.

38. Lawes CM, Parag V, Bennett DA, Suh I, Lam TH, Whitlock G, Barzi F Woodward M: Blood glucose and risk of cardiovascular disease in the Asia Pacific region. Diabetes Care 2004, 27:2836-2842.

39. Sorkin JD, Muller DC, Fleg JL, Andres R: The relation of fasting and 2-h postchallenge plasma glucose concentrations to mortality: data from the Baltimore Longitudinal Study of Aging with a critical review of the literature. Diabetes Care 2005, 28:2626-2632

40. Lin H, Lee E, Hestir K, Leo C, Huang M, Bosch E, Halenbeck R, Wu G, Zhou A, Behrens D, Hollenbaugh D, Linnemann T, Qin M, Wong J, Chu K, Doberstein SK, Williams LT: Discovery of a cytokine and its receptor by functional screening of the extracellular proteome. Science 2008, 320:807-811.

41. Shikata K, Makino H: Role of macrophages in the pathogenesis of diabetic nephropathy. Contrib Nephrol 2001, 134:46-54.

42. Tesch GH: Role of macrophages in complications of type 2 diabetes. Clin Exp Pharmacol Physiol 2007, 34:1016-1019.

43. Navarro-Gonzalez JF, Mora-Fernandez C, Muros De Fuentes M, Garcia-Perez $\mathrm{J}$ : Inflammatory molecules and pathways in the pathogenesis of diabetic nephropathy. Nat Rev Nephrol 2011, 7:327-340.

44. Navarro-Gonzalez JF, Mora-Fernandez C: The role of inflammatory cytokines in diabetic nephropathy. J Am Soc Nephrol 2008, 19:433-442.

45. Zhang $Y$, Zhang Q: Bone morphogenetic protein-7 and gremlin: new emerging therapeutic targets for diabetic nephropathy. Biochem Biophys Res Commun 2009, 383:1-3.

46. Kanwar YS, Sun L, Xie P, Liu FY, Chen S: A glimpse of various pathogenetic mechanisms of diabetic nephropathy. Annu Rev Pathol 2011, 6:395-423.

47. Wang S, de Caestecker M, Kopp J, Mitu G, Lapage J, Hirschberg R: Renal bone morphogenetic protein-7 protects against diabetic nephropathy. J Am Soc Nephrol 2006, 17:2504-2512

48. Wang S, Chen Q, Simon TC, Strebeck F, Chaudhary L, Morrissey J, Liapis H, Klahr S, Hruska KA: Bone morphogenic protein-7 (BMP-7), a novel therapy for diabetic nephropathy. Kidney Int 2003, 63:2037-2049.

49. McKnight AJ, Pettigrew KA, Patterson CC, Kilner J, Sadlier DM, Maxwell AP, Warren UKGSG: Investigation of the association of BMP gene variants with nephropathy in Type 1 diabetes mellitus. Diabet Med 2010, 27:624-630

50. Yang HC, Lin CH, Hsu CL, Hung SI, Wu JY, Pan WH, Chen YT, Fann CS: A comparison of major histocompatibility complex SNPs in Han Chinese residing in Taiwan and Caucasians. J Biomed Sci 2006, 13:489-498.

51. Liu ZH, Guan TJ, Chen ZH, Li LS: Glucose transporter (GLUT1) allele (Xbal-) associated with nephropathy in non-insulin-dependent diabetes mellitus. Kidney Int 1999, 55:1843-1848.

52. Hsieh MC, Lin SR, Hsieh TJ, Hsu CH, Chen HC, Shin SJ, Tsai JH: Increased frequency of angiotensin-converting enzyme DD genotype in patients with type 2 diabetes in Taiwan. Nephrol Dial Transplant 2000, 15:1008-1013. 
53. Huo $P$, Zhang $D$, Guan $X$, Mei $Y$, Zheng $H$, Feng $X$ : Association between genetic polymorphisms of ACE \& eNOS and diabetic nephropathy. Mol Biol Rep 2014, [Epub ahead of print] doi:10.1007/s11033-014-3736-y.

54. Liu L, Zheng T, Wang N, Wang F, Li M, Jiang J, Zhao R, Li L, Zhao W, Zhu Q, Jia W: The manganese superoxide dismutase Val16Ala polymorphism is associated with decreased risk of diabetic nephropathy in Chinese patients with type 2 diabetes. Mol Cell Biochem 2009, 322:87-91.

55. Maeda S, Kobayashi MA, Araki S, Babazono T, Freedman BI, Bostrom MA, Cooke JN, Toyoda M, Umezono T, Tarnow L, Hansen T, Gaede P, Jorsal A, Ng DP, Ikeda M, Yanagimoto T, Tsunoda T, Unoki H, Kawai K, Imanishi M, Suzuki D, Shin HD, Park KS, Kashiwagi A, Iwamoto Y, Kaku K, Kawamori R, Parving HH, Bowden DW, Pedersen O, et al: A single nucleotide polymorphism within the acetyl-coenzyme A carboxylase beta gene is associated with proteinuria in patients with type 2 diabetes. PLOS Genet 2010, 6:e1000842.

56. Liu L, Zheng T, Wang F, Wang N, Song Y, Li M, Li L, Jiang J, Zhao W: Pro12Ala polymorphism in the PPARG gene contributes to the development of diabetic nephropathy in Chinese type 2 diabetic patients. Diabetes Care 2010, 33:144-149.

57. Tang SC, Leung VT, Chan LY, Wong SS, Chu DW, Leung JC, Ho YW, Lai KN, Ma L, Elbein SC, Bowden DW, Hicks PJ, Comeau ME, Langefeld CD, Freedman BI: The acetyl-coenzyme A carboxylase beta (ACACB) gene is associated with nephropathy in Chinese patients with type 2 diabetes. Nephrol Dial Transplant 2010, 25:3931-3934.

58. Zhang H, Wang J, Yi B, Zhao Y, Liu Y, Zhang K, Cai X, Sun J, Huang L, Liao Q: Bsml polymorphisms in vitamin $D$ receptor gene are associated with diabetic nephropathy in type 2 diabetes in the Han Chinese population. Gene 2012, 495:183-188.

59. Zhou J, Peng R, Li T, Luo X, Peng H, Zha H, Yin P, Wen L, Zhang Z: A potentially functional polymorphism in the regulatory region of let-7a-2 is associated with an increased risk for diabetic nephropathy. Gene 2013, 527:456-461.

60. Wu HY, Wang Y, Chen M, Zhang X, Wang D, Pan Y, Li L, Liu D, Dai XM Association of ELMO1 gene polymorphisms with diabetic nephropathy in Chinese population. J Endocrinol Invest 2013, 36:298-302.

61. Schmid H, Boucherot A, Yasuda Y, Henger A, Brunner B, Eichinger F, Nitsche A, Kiss E, Bleich M, Grone HJ, Nelson PJ, Schlöndorff D, Cohen CD, Kretzler M, European Renal CDNA Bank (ERCB) Consortium: Modular activation of nuclear factor-kappaB transcriptional programs in human diabetic nephropathy. Diabetes 2006, 55:2993-3003.

62. Woroniecka Kl, Park AS, Mohtat D, Thomas DB, Pullman JM, Susztak K: Transcriptome analysis of human diabetic kidney disease. Diabetes 2011, 60:2354-2369.

63. Hodgin JB, Nair V, Zhang H, Randolph A, Harris RC, Nelson RG, Weil EJ, Cavalcoli JD, Patel JM, Brosius FC 3rd, Kretzler M: Identification of crossspecies shared transcriptional networks of diabetic nephropathy in human and mouse glomeruli. Diabetes 2013, 62:299-308.

\section{Submit your next manuscript to BioMed Central and take full advantage of:}

- Convenient online submission

- Thorough peer review

- No space constraints or color figure charges

- Immediate publication on acceptance

- Inclusion in PubMed, CAS, Scopus and Google Scholar

- Research which is freely available for redistribution 